\title{
STUDY OF ADHESION CHARACTERISTICS AND SURFACE INTERACTION OF BITUMEN AND FLY- ASH FROM POWER PLANTS
}

\author{
[Lebedev Mikhail Sergeevich, Limarenko Mikhail Vitalievich, Kozhukhova Natalia Ivanovna]
}

\begin{abstract}
Study of processes and mechanisms of realization of them in contact zone for construction composite materials is a very big problem. For fly ash (FA) based bitumen-mineral compositions studied in this paper adhesive strength between bitumen and FA particles is the base factor effected on properties of road-building material. Earlier was reported that low-calcium FA (type F) from Omsk power station (Russia) can adsorb much more content of bitumen vs. high-calcium one from Nazarovsk power station (Russia). It can be connected not only with structure as well as physical and mechanical characteristics of bitumen-mineral compositions but surface energy effect when bitumen and fly ash interaction. It is studied in this research.
\end{abstract}

Adhesion between bitumen and FA particles was determined by adsorption/desorption effect of bitumen as well as energy between two contacted surfaces. It was found, that F-type FA has a quite high adsorption capacity. At the same time adsorption capacity for C-type FA to bitumen based on benzene solution is low. The results obtained are in agreement with calculated data for adhesion between bitumen and mineral particles of FA: adhesion for F-type FA-based composites is higher vs. type Cbased ones.

It takes place independently of equal values of surface energy for a both types of FA. The data obtained demonstrate the best adhesion of bitumen to FA particles is realized in case of surface interaction by dispersion (Lifshitz-van der Waals) forces. This type of interaction is typical for F-type FA. For C-type FA almost $1 / 3$ of total work of adhesion is consumed on polar (acid-basic) interactions and effect from dispersion force is twice lower vs. Ftype FA.

So, data of bitumen adsorption and interaction energy in contact zone «FA - bitumen» explain physical and mechanical properties of bitumen-mineral composites based on different types of FA (with different composition and particle size)

Lebedev Mikhail Sergeevich

Belgorod State Technological University named after V.G. Shoukhov Russia

Limarenko Mikhail Vitalievich

Belgorod State Technological University named after V.G. Shoukhov Russia

Kozhukhova Natalia Ivanovna

Belgorod State Technological University named after V.G. Shoukhov Russia
Keywords - fly ash from power plants, wetting effect, surface energy, work of adhesion, adsorption/desorption effect of bitumen

\section{Introduction}

Development of high-performance construction composite material consisting of two and more of components requires understanding of many structure-forming parameters such as adhesion strength between components in contact zone as the weakest area in the composite. Especially, it is typical for bitumen-mineral composites where adhesion of bitumen to mineral particles of filler is a crucial factor effecting on such basic characteristics of road-building material as water requirement, water-resistance, freeze-thaw resistance etc.

Adhesion strength between bitumen and finely dispersed fillers like FA can be determined by adsorption/desorption capacity of material to bitumen from different solvents (benzene, methyl benzene etc.). Chemical adsorption of binder is determined by bitumen content, adsorbed onto the surface of filler [1-5]. However, this method gives data of content of adsorbed bitumen only but does not allow deep understanding of this process realization and determination of interaction force between components.

Many scientists from Russia and others countries believe, that main factor when interaction of organic binder and mineral filler is energy potential of mineral particle surface. Surface molecules of solids are subjected to unbalanced forces vs. molecules in that leads to extra surface energy, equal to lack of cohesive energy inside. Extra surface energy is called as «free surface energy». Direct methods of determination of this parameter are absent. Normally, energy potential determination is realized by calculation with data on adsorption or thermodynamics of processes.

Thermodynamic methods of free energy determination are based on wetting effect. Often, the Good-van Oss-Chaudhury theory is applied in works with bitumen concrete. The theory is based on measurement of work of adhesion of studied material to liquids, gases and fumes and following determination of general surface energy as well as classification of its constituents according to type of surface molecular force [6]:

- Non-polar component called as Lifshitz-van der Waals or dispersing component $\left(\gamma^{\mathrm{LW}}\right)$;

- Lewis acidic component $\left(\gamma^{+}\right)$;

- Lewis basic component $\left(\gamma^{-}\right)$. 
Proc. of the Sixth International Conference on Advances in Civil, Structural and Environmental Engineering - ACSEE 2017. Copyright (C) Institute of Research Engineers and Doctors. All rights reserved.

ISBN: 978-1-63248-139-9 doi: 10.15224/ 978-1-63248-139-9-22

According to this theory, work of adhesion $W_{S L}$ between two materials $\mathrm{S}$ and $\mathrm{L}$ taking into account of free surface energy of them can be presented by following:

$$
W_{S L}=2 \sqrt{\gamma_{S}^{L W} \times \gamma_{L}^{L W}}+2 \sqrt{\gamma_{S}^{+} \times \gamma_{L}^{-}}+2 \sqrt{\gamma_{S}^{-} \times \gamma_{L}^{+}}
$$

The eq. (1) is applied for calculation of surface energy of solid material $\mathrm{S}$ when wetting or adhesion to liquid component $\mathrm{L}$ with fixed constituents of surface energy. Usually, liquids characterized by surface tension are used. For the system «FA (S-component) - bitumen (L-component)» this equation can be used for calculation of work of adhesion at the interface in case, all components of free surface energy of the both components are known.

According to this method, to describe dispersing and polar (acidic and basic separately) constituents of surface energy the following liquids are applied: non-polar liquid in number of 1 and polar liquids in number of 2 . One of polar liquids contents contains acidic and basic constituents in equal parts (distilled water). Other one consists of the same parameters with nonzero values.

One of the most common methods for measurement of work of adhesion is measurement of contact angle at interface «solid-liquid» [7]. In this caseб work of adhesion can be calculated with Young-Dupré equation that makes relation between bond energy and materials with two experimental parameters: contact angle $\theta$ and liquid tension $\gamma$.

$$
W_{S L}=\gamma_{L}^{\text {TOTAL }}(1+\cos \theta)
$$

Using eq. (1) and (2) together as well as parameters of contact angle and such liquid characteristics as $\gamma_{L}^{T O T A L}, \gamma_{L}{ }^{L W}$, $\gamma_{L}^{+}, \gamma_{L}^{-}$, we can calculate parameters $\gamma_{S}{ }^{L W}, \gamma_{S}{ }^{+}, \gamma_{S}^{-}$for FA (or other S-material) by solution of simultaneous equations, where each of one folds for standard liquids. Polar constituents $\gamma_{S}{ }^{A B}$ and total free surface energy $\gamma_{S}^{\text {TOTAL }}$ was calculated by eq. (3)

$$
\begin{gathered}
\gamma_{S}^{A B}=2 \sqrt{\gamma_{S}^{+} \times \gamma_{S}^{-}} \\
\gamma_{S}^{T O T A L}=\gamma_{S}^{L W}+\gamma_{S}^{A B}
\end{gathered}
$$

In case of interaction of bitumen and FA it should to use term «interfacial energy» - free energy, required for increasing of interfacial surface (or interaction surface) between two phases and can be shown as in eq. (5)

$$
\gamma_{F A-\text { Bitumen }}=\gamma_{F A}+\gamma_{\text {Bitumen }}-\Delta G_{F A-\text { Bitumen }}
$$

where $\gamma_{F A}$ is surface energy of FA; $\gamma_{B i t u m e n}$ is surface energy of bitumen; $\Delta G_{F A-B i t u m e n}$ is work of adhesion between two phases [8].

Regarding interaction of FA and bitumen, earlier by authors [9] was reported, F-type FA from Omsk power plant is characterized by significant adsorption capacity to bitumen vs. C-type FA from Nazarovsk power plant. Low adsorption capacity of C-type FA leads to flacking of bitumen layer and hydration of reactive mineral component with following formation of new phases. Reasons in differences between physical and mechanical characteristics of bitumen-mineral composites are in potential energy of surface interaction of the system «FA-bitumen». It was detaily studied in this work.

\section{Experimental part}

\section{A. Materials}

Two following types of FA from Russian power plants with different chemical composition, porosity and specific surface (Table I) were applied: C-type FA from Nazarovsk power plant and F-type FA from Omsk power plant

TABLE I. CHARACTERISTICS OF FAS

\begin{tabular}{|l|c|c|c|}
\hline \multicolumn{2}{|c|}{ Parameter } & C-type FA & F-type FA \\
\hline $\begin{array}{l}\text { Chemical } \\
\text { composition, }\end{array}$ & $\mathrm{SiO}_{2}$ & 31,55 & 55,33 \\
\cline { 2 - 4 } wt.\% & $\mathrm{Al}_{2} \mathrm{O}_{3}$ & 8,84 & 29,92 \\
\cline { 2 - 4 } & $\mathrm{CaO}$ & 37,80 & 2,57 \\
\hline $\begin{array}{l}\text { Spesific surface area by } \\
\text { Blain/BET, } \mathrm{m}^{2} / \mathrm{kg}\end{array}$ & $347,4 / 1100$ & $291,6 / 5900$ \\
\hline \multicolumn{2}{|l}{ Porosity,. \% } & 30,9 & 39,5 \\
\hline
\end{tabular}

Bitumen BND 60/90 (Russia) was used as binding component.

\section{B. Methods}

Free surface energy of bitumen and FA was determined using data of contact angles with standard liquids. For bitumen direct measurements of contact angles by Sessile Drop Method using KRUSS DSA30 apparatus was realized. Bitumen samples were used in pellet form. Three followings standard liquids were chosen according to Good-van Oss-Chaudhury

\begin{tabular}{|c|c|c|c|c|c|}
\hline $\begin{array}{l}\text { Standard } \\
\text { liquid }\end{array}$ & $\begin{array}{l}\gamma_{\mathrm{L}}^{\text {TOTAL }} \\
\mathbf{m} \mathbf{J} / \mathbf{m}^{2}\end{array}$ & $\begin{array}{l}\gamma_{\mathrm{L}}^{\mathrm{LW}}, \\
\mathbf{m} \mathbf{J} / \mathbf{m}^{2}\end{array}$ & $\begin{array}{c}\gamma_{\mathbf{L}}{ }^{\mathrm{AB}}, \\
\mathbf{m} \mathbf{J} / \mathbf{m}^{2}\end{array}$ & $\begin{array}{c}\gamma_{\mathrm{L}}{ }^{+}, \\
\mathbf{m} \mathbf{J} / \mathbf{m}^{2}\end{array}$ & $\begin{array}{c}\gamma_{\mathbf{L}}^{-}, \\
\mathbf{m J} / \mathbf{m}^{2}\end{array}$ \\
\hline Distilled water & 72,8 & 21,8 & 51,0 & 25,5 & 25,5 \\
\hline diiodomethane & 50,8 & 50,8 & 0 & 0,01 & 0 \\
\hline glycerine & 64 & 34 & 30 & 3,92 & 57,4 \\
\hline n-hexane & 18,4 & 18,4 & 0 & 0 & 0 \\
\hline formamide & 58,0 & 39,0 & 19,0 & 2,28 & 39,6 \\
\hline $\begin{array}{l}\text { 1-bromo- } \\
\text { naphthalene }\end{array}$ & 44,4 & 44,4 & $\approx 0$ & $\approx 0$ & $\approx 0$ \\
\hline
\end{tabular}
method: distilled water, diiodomethane and glycerine (Table II) $[6,10]$.

TABLE II. CHARACTERISTICS OF STANDARD LIQUIDS, USED FOR CONTACT ANGLE AND SURFACE TENSION ENERGY $[6,10]$

Contact angles for FA were determined by Capillary rise method (Washburn), consisting of liquid lifting with capillaries, those are formed in bulk powder, due to capillary forces. At the same time, when liquid penetrates into complex of capillaries (pores) with radius $r$, lifting height $h$ and lifting time $t$ are related by the following equation: 
Proc. of the Sixth International Conference on Advances in Civil, Structural and Environmental Engineering - ACSEE 2017. Copyright ( $\odot$ Institute of Research Engineers and Doctors. All rights reserved.

ISBN: 978-1-63248-139-9 doi: 10.15224/ 978-1-63248-139-9-22

$$
h^{2}=\frac{(c r) y t \cos \theta}{2 \eta}
$$

where $h$ is lifting height of liquid during the time $t ; \gamma$ is surface tension energy of liquid; $r$ is capillary radius; $\Theta$ is growing contact angle; $\eta$ is liquid viscosity; $c$-coefficient is used for randomly oriented capillaries (capillary coefficient) [11-15].

Parameter ( $c r$ ) was calculated taking account, the liquid with low surface tension completely wets a solid surface (i.e. $\Theta=0^{\circ}$ and $\left.\operatorname{Cos} \Theta=1\right)$. For this purpose in the work an n-hexane was used due to its low surface tension at r.t. After determination of $c$-coefficient this sample also was tested with others standard liquids: distilled water, formamide and 1bromo-naphthalene (Table 2). According to eq. (6) contact angle $\Theta$ was calculated with eq. (7)

$$
\cos \theta=\frac{h^{2}}{t} \times \frac{2 \eta}{\gamma(c r)}
$$

Adsorption capacity of FA relating to bitumen was determined by adsorption method of organic binder from benzene solutions. The method was realized by following: four solutions of bitumen in benzene with different concentration of bitumen: 1, 3, 6, $9 \mathrm{~g} / 1$. For these solutions optical density with spectrophotometer SF-56 was measured as well as calibration schedule of effect of concentration of bitumen on optical density was plotted.

Samples of FA (5g) was placed in four glass flasks containing $50 \mathrm{ml}$ of solutions with the above concentrations with following shaking for an hour. The obtained suspensions were in state of rest for an hour followed by centrifugal separation up to complete decantation. For residual liquid optical density was measured to determine of its concentration (with calibration schedule). Adsorption was calculated with eq. (8).

$$
A=\frac{\left(C_{0}-C\right) V}{1000 m}
$$

where $\mathrm{C}_{0}$ is initial concentration of solution, $\mathrm{kg} / \mathrm{m}^{3} ; \mathrm{C}$ is equilibrium concentration of solution, $\mathrm{kg} / \mathrm{m}^{3} ; \mathrm{V}$ is solution volume, $\mathrm{m}^{3} ; \mathrm{m}$ is mass of $\mathrm{FA}, \mathrm{kg}$.

Content of bitumen chemically bonded with surface of FA particles was determined by difference between values of desorption and adsorption of bitumen. Method includes flushing of FA with adsorbed bitumen by $50 \mathrm{ml}$ of clear benzene solution followed by optical density determination. Concentrations determined with calibration schedule.

\section{Results and discussions}

\section{A. Surface energy of bitumen}

Drop shape for different standard liquids at bitumen surface and values of contact angles (Table III) are differed. Calculated values of constituents of surface energy are shown in Table IV.
TABLE III. CONTACT ANGLES BETWEEN STANDARD LIQUIDS AND SOLID SURFACE

\begin{tabular}{|c|c|c|}
\hline Distilled water & Diiodomethane & Glycerine \\
\hline $105,64 \pm 1,29^{\circ}$ & $57,01 \pm 2,62^{\circ}$ & $99,87 \pm 4,32^{\circ}$ \\
\hline
\end{tabular}

TABLE IV. SURFACE ENERGY OF BITUMEN, MEASURED BY SESSILE DROP METHOD

\begin{tabular}{|c|c|c|c|c|}
\hline $\begin{array}{c}\gamma^{\mathrm{TOTAL}}, \mathbf{2} \\
\mathbf{m J} / \mathbf{m}^{2}\end{array}$ & $\gamma^{\mathrm{LW}}, \mathbf{m J} / \mathbf{m}^{2}$ & $\gamma^{\mathrm{AB}}, \mathbf{m J} / \mathbf{m}^{2}$ & $\gamma^{+}, \mathbf{m J} / \mathbf{m}^{2}$ & $\gamma^{-}, \mathbf{m J} / \mathbf{m}^{2}$ \\
\hline 32,91 & 30,30 & 2,61 & 1,12 & 1,52 \\
\hline
\end{tabular}

According to data from Table 4 surface energy consists of $92.07 \%$ of non-polar interaction forces (Lifshitz-van der Waals forces) and $7.93 \%$ of polar ones. Thus, bitumen is generally, non-polar material, which interacts with solids through dispersion (electrostatic) forces, affecting for a long distance (more than $100 \AA$ ). It is fully in agreement with earlier studies devoted to determination of bitumen surface energy $[8$, $16,17]$. Also, it is assumed that petroleum bitumen contains compounds with low acidic and basic functional groups, that is confirmed by experimental data (Table IV).

It can be proposed, interaction of bitumen and FA is realized, generally, by dispersion forces. Polar (acidic-basic) forces are not significant and influence of them can be major in case of high surface polarity. So, the best adhesion between bitumen and solids with high surface energy takes place. Effect of forces providing adhesion effect depends of polar and non-polar constituents (virgin and surface charge of them) of surface energy.

\section{B. Surface energy of FA}

Washburn method with $n$-hexane as liquid with the best wetting effect is effective for F-type FA. For C-type FA, calculated values of cos-value of contact angles for formamide and 1-bromo-naphthalene using the same method are more than 1 (Table V). It is due to the both two liquids wet FA particles better vs. n-hexane. Calculation of capillary radius (cr) was realized using 1-bromo-naphthalene as standard liquid, which completely wets solids surface and provides the highest cos-value of contact angle.

TABLE V. COS-VALUE FOR CONTACT ANGLES BETWEEN C-TYPE FA AND STANDARD LIQUIDS $\left(\Theta=0^{\circ}\right.$ FOR N-HEXANE)

\begin{tabular}{|c|c|l|c|}
\hline \multicolumn{4}{|c|}{ Standard liquid } \\
\hline $\begin{array}{c}n- \\
\text { hexane }\end{array}$ & \multicolumn{1}{|c|}{ Distilled water } & formamide & $\begin{array}{c}\text { 1-bromo- } \\
\text { naphthalene }\end{array}$ \\
\hline 1 & 0,728 & 1,189 & 1,571 \\
\hline
\end{tabular}

Data of contact angles and calculated value of constituents of surface area are shown in Table VI and VII, respectively.

TABLE VI. SURFACE ENERGY OF FA, MEASURED BY GOOD-VAN OSSCHAUDHURY METHOD

\begin{tabular}{|c|l|l|l|l|l|}
\hline Filler & $\begin{array}{c}\gamma_{\mathbf{s}}{ }^{\text {TOTAL }} \\
\mathbf{m} \mathbf{J} / \mathbf{m}^{\mathbf{2}}\end{array}$ & $\begin{array}{c}\boldsymbol{\gamma}_{\mathbf{s}}{ }^{\mathbf{L W}}, \\
\mathbf{m} \mathbf{J} / \mathbf{m}^{\mathbf{2}}\end{array}$ & $\begin{array}{c}\boldsymbol{\gamma}_{\mathbf{s}}{ }^{\mathbf{A B}}, \\
\mathbf{m} \mathbf{J} / \mathbf{m}^{\mathbf{2}}\end{array}$ & $\begin{array}{c}\boldsymbol{\gamma}_{\mathbf{s}}{ }^{+}, \\
\mathbf{m} \mathbf{J} / \mathbf{m}^{\mathbf{2}}\end{array}$ & $\boldsymbol{\gamma}_{\mathbf{s}}{ }^{-}, \mathbf{m} \mathbf{J} / \mathbf{m}^{\mathbf{2}}$ \\
\hline C-type FA & 39,02 & 11,95 & 27,07 & 14,73 & 12,44 \\
\hline F-type FA & 38,73 & 37,37 & 1,36 & 0,01 & 33,05 \\
\hline
\end{tabular}


Proc. of the Sixth International Conference on Advances in Civil, Structural and Environmental Engineering - ACSEE 2017. Copyright (c) Institute of Research Engineers and Doctors. All rights reserved.

ISBN: 978-1-63248-139-9 doi: 10.15224/ 978-1-63248-139-9-22

Data from Table VII demonstrate that two types of FA have comparable values of surface energy, but significant differences in some constituents of it for two FA are observed (Table VII). For F-type FA total surface energy is, generally, consists of non-polar (dispersion) constituent, $\gamma_{\mathrm{S}}{ }^{\mathrm{AB}}$ that is equal to $1.36 \mathrm{~mJ} / \mathrm{m}^{2}$. Contribution of non-polar constituent into surface energy of C-type FA is up to $30 \%$ and polar constituent $-70 \%$. In this case acidic and basic constituents are equal.

So, we can conclude, C-type FA consists of charged phases like anhydrite $\mathrm{CaSO}_{4}$, portlandite $\mathrm{Ca}(\mathrm{OH})_{2}$, lime $\mathrm{CaO}$, tricalcium aluminate $3 \mathrm{CaO} \cdot \mathrm{Al}_{2} \mathrm{O}_{3}$ [9]. Surface of F-type FA is uncharged.

\section{Energy potential of «FA - bitumen» interaction}

It is known, reducing of interfacial energy leads to improving a wetting effect in system «liquid - solid», i.e. growing of contact area is accelerated. So, less interfacial energy initiates a better «liquid - solid» interaction. In this study F-type FA has a lower interfacial energy, so a better interaction with bitumen vs. C-type FA (Table VIII).

This effect was confirmed by data of work of adhesion: for C-type FA this parameter is significantly lower vs. F-type FA and vs. work of cohesion for bitumen. It means that molecules of organic binder have a better affinity with similar liquid materials vs. solids. The result is incomplete wetting of solid surface. For F-type FA, opposite effect is observed (Table VIII). It is confirmed by visual analysis when mixing of bitumen and FA.

High value of work of adhesion in system « F-type FA bitumen» explains good adhesion of bitumen to FA particles due to work of adhesion characterizes adhesion energy.

TABLE VII. CONTACT ANGLES BETWEEN STANDARD LIQUIDS AND SURFACE OF FA MEASURED BY WASHBURN METHOD

\begin{tabular}{|c|c|c|c|c|}
\hline \multirow{2}{*}{ Filler } & \multicolumn{4}{|c|}{ Standard liquid } \\
\cline { 2 - 5 } & $\begin{array}{c}\boldsymbol{n} \text { - } \\
\text { hexan } \\
\boldsymbol{e}\end{array}$ & $\begin{array}{c}\text { Distilled } \\
\text { water }\end{array}$ & $\begin{array}{c}\text { formami } \\
\boldsymbol{d e}\end{array}$ & $\begin{array}{c}\text { 1-bromo- } \\
\text { naphthalene }\end{array}$ \\
\hline C-type FA & 50,14 & 62,28 & 40,46 & 0 \\
\hline F-type FA & 0 & 55,58 & 53,84 & 33,40 \\
\hline
\end{tabular}

TABLE VIII. ENERGY POTENTIAL OF «FA - BITUMEN» INTERACTION

\begin{tabular}{|c|c|c|c|c|c|}
\hline Filler & 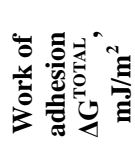 & 乌气 & 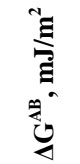 & 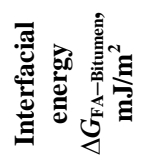 & 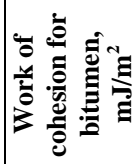 \\
\hline C-type FA & 54,99 & 38,06 & 16,93 & 16,94 & \multirow{2}{*}{65,82} \\
\hline F-type FA & 79,71 & 67,30 & 12,41 & $-8,07$ & \\
\hline
\end{tabular}

As we proposed, work of adhesion is realized through dispersion forces $(69.0 \%$ for C-type FA and $84.5 \%$ for F-type FA) that is represented in Table VIII. The data allow conclusion, that for C-type FA $1 / 3$ of all interactions is accomplished by polar forces. Non-polar force effected for Ftype FA is twice as much as for C-type FA.

Thus, better adhesion bitumen to solid material with higher surface energy where dispersion (Lifshitz-van der Waals) forces are major.

\section{Adsorption/desorption effect between bitumen and $F A$}

Calculated data for surface energy and energy potential of «FA - bitumen» interaction are confirmed by experimental data of adsorption/desorption effect of bitumen from benzene solutions at surface of FA particles.

For F-type FA a higher adsorption capacity to bitumen vs. C-type FA (Fig. 1) the highest adsorption is observed for concentration of benzene solution of $9 \mathrm{~g} / \mathrm{l}\left(2.5 \cdot 10^{-5}\right.$ $\left.\mathrm{kg}_{\text {bitumen }} / \mathrm{kg}_{\mathrm{FA}}\right)$. In this case, considerable part of bitumen is strongly bonded with FA particles. That is explained by low desorption values (up to $24 \%$ for all concentrations). According to these data F-type FA has a good adhesion with bitumen due to non-polar forces, chemical adsorption as well as due to penetration of some organic components into pore space of the particles.

Opposite results for C-type FA are typical. C-type FA is reactive component in composite materials, including bitumen-mineral binders due to presence of $\mathrm{CaO}_{\text {free }}$, clinker minerals and others Ca-bearing components. However, adsorption effect at C-type FA surface almost absents.

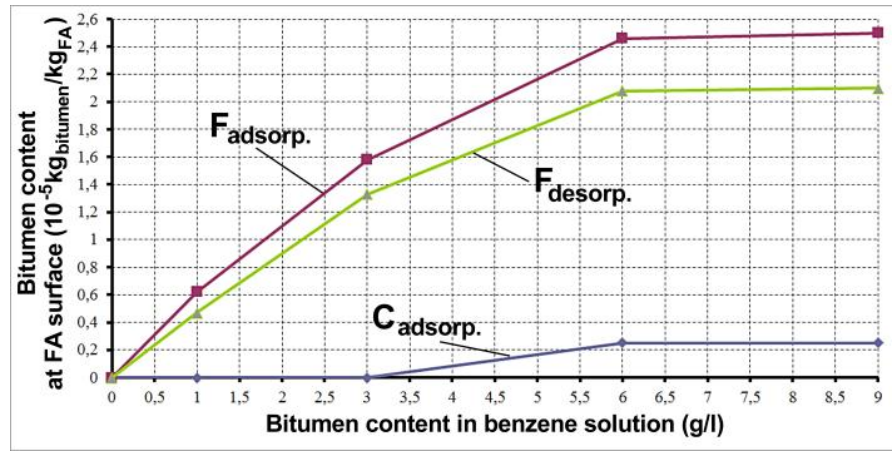

Figure 1. Adsorption/desorption effect at surface of different FA: $\mathrm{C}_{\text {adsorb. }}$ and $\mathrm{F}_{\text {adsorb. }}$ - adsorption for C-type FA and F-type FA, respectivelly; $\mathrm{F}_{\text {desorp. }}-$ desorption for F-type FA

Even at the highest concentration $(9 \mathrm{~g} / \mathrm{l})$ it is equal to $0.25 \cdot 10^{-5} \kappa \Gamma_{\text {bitumen }} / \kappa \Gamma_{\mathrm{FA}}$. Due to low adsorption, «FA bitumen» desorption effect was not studied

\section{Summary.}

Results, obtained in this research demonstrate, F-type FA has a higher adsorption capacity to bitumen vs. C-type FA, confirming earlier results of physical and mechanical 
Proc. of the Sixth International Conference on Advances in Civil, Structural and Environmental Engineering - ACSEE 2017. Copyright (๑) Institute of Research Engineers and Doctors. All rights reserved. ISBN: 978-1-63248-139-9 doi: 10.15224/ 978-1-63248-139-9-22

characteristics for bitumen-mineral composites. Data of adhesion and adsorption are in agreement with energy potential of $« \mathrm{~F}-$ bitumen» interaction, calculated with surface energy for both components. Bitumen wetting effect for a both FA is realized differently whereas equal values of surface energy.

Explanation of data of work of adhesion and interfacial energy can be realized by origin of interaction forces as well as values of surface energy constituents and ratio of them. Ftype FA has a more content of dispersion forces, effecting on work of adhesion. Bitumen as non-polar component has a higher affinity with F-type FA vs. C-type FA.

C-type FA contains more of $2 / 3$ of polar constituent of surface energy. So, non-polar constituent initiates $1 / 3$ of work of adhesion of bitumen to FA only. Total value of $\Delta \mathrm{G}^{\mathrm{TOTAL}}$ is lower vs. work of cohesion of bitumen resulting in slight wetting effect of FA.

So, adsorption/desorption effect for bitumen as well as energy potential of «FA- bitumen» interaction explain experimental data of physical and mechanical characteristics of «FA- bitumen» composites.

\section{Acknowledgment}

This research work is financially supported by Ministry of Education and Science of Russian Federation in framework of State Assignment №11.9329.2017/8.9, Russian Federation Ministry of Education and Science in the framework of the Presidential Scholarship № PS-2099.2015.1, using equipment of High Technology Center at BSTU named after V.G. Shoukhov.

\section{References}

[1] A.V. Bituev and K.A. Bosholov, "Silica-bearing mineral powders for asphalt concrete", Bulletin of TGASU, №3, 2007, pp. 210-212.

[2] M.A. Vysotskaya, D.A. Kuznetsov and D.E. Barabash, "Features of structure formation in bitumen-mineral compositions using porous raw", Construction materials, №1-2, 2014, pp. 68-71.

[3] M.A. Vysotskaya, V.V. Yadykina and D.A. Kuznetsov, "Lime in asphalt concrete is so simole and conplex one", Construction materials, № 3, 2006, pp. 56-58.

[4] A.A. Soldatov and Yu.G. Borisenko, "Surface structure of porous powders based on screenings of keramzite grinding and adsorption activity of them", Construction materials, №6, 2011, pp. 36-38.

[5] V.V. Yadykina and N.P. Kutsyina, "Study of bitumen adsorbtion at surface of fiber materials", Bulletin of BSTU named after V.G. Shoukhov, № 9, 2005, pp. 441.

[6] C.J. van Oss, M.K. Chaudhury and R.J. Good, "Interfacial Lifshitz-van der Waals and Polar Interactions in Macroscopic Systems", Chemical Reviews, vol. 88, 1988, pp. 927-941.

[7] T. Young, "An essay on the cohesion of fluids", Phil. Trans. Royal Society (London), Vol. 95, 1805, pp. 65-87.

[8] R. Taylor, Surface interactions between bitumen and mineral fillers and their effects on the rheology of bitumen-filler mastics, Ph.D. thesis, Univ. of Nottingham, UK., 2007, 238 p.

[9] M.S. Lebedev, N.I. Kozhukhova and I.L. Chulkova, "Effect of phase and size characteristics of fly ash from power station on properties of bitumen composites". IOP Conf. Series: Materials Science and Engineering, Vol. 222, 2017.
[10] C. J. van Oss, Interfacial Forces in Aqueous Media, 2nd ed., CRC Press, Boca Raton, FL, 2006.

[11] E.W. Washburn, "Physical Review", vol. 1, 1921, pp. 273 (in Ref. 24).

[12] H.G. Bruil and van J.J. Aartsen, "Colloid \& Polymer Science", vol. 252, 1974, pp. 32-38.

[13] A.W. Adamson, Physical Chemistry of Surfaces, 5th ed., John Wiley and Sons, 1990.

[14] C.A. Ku, J.D. Henry, R. Siriwardane and L.J. Roberts, "Colloids and Interface Sci.", vol. 106, 1985, pp. 377-385.

[15] A.D. Zimon, Adhesion of liquid and wetting, Moscow: Chemistry, 1974, $416 \mathrm{p}$.

[16] A. Bhasin, Development of methods to quantify bitumen-aggregate adhesion and loss of adhesion due to water, Ph.D. thesis, Texas A\&M University, USA, 2006, 146 p.

[17] A.W. Hefer, Adhesion in bitumen-aggregate systems and quantification of the effects of water on the adhesive bond, Ph.D. dissertation, Texas A\&M University, USA, 2004, 209 p.

About Author s:

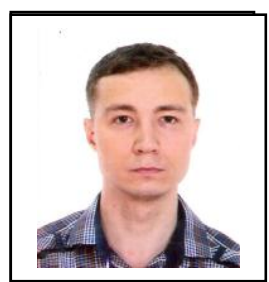

Dr. Mikhail Lebedev focuses on study of mineral fillers with different phase and size heterogeneity in organic (bitumen) binding systems.

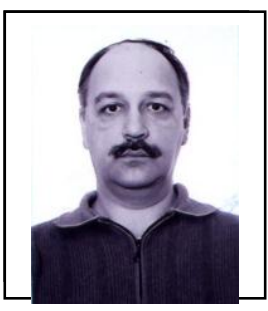

Mikhail Limarenko focuses on studies in area of thin layers, magnetoelectric, ferromagnetic, protective coatings synthesized by magnetron sputtering from boridebased materials.

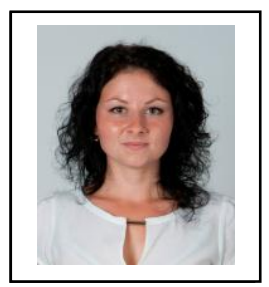

Dr. Natalia Kozhukhova focuses on the investigations in area of synthesis and study of free-ofcement construction materials using mineral components of natural, synthetic and industrial origin. 